\title{
CAMINO SAGRADO, CAMINO DE VIOLENCIA Y PODER EN LA CORDILLERA DEL PARIACACA
}

\author{
Sacred Road, Road of Violence and Power in the Pariacaca Mountain Range
}

\author{
Carlos Farfan Lobaton \\ farfancarlos574@gmail.com \\ Universidad Nacional Federico Villarreal. Perú
}

Fecha de recepción: 04/02/2021

Fecha de aceptación: 02/05/2021

Resumen: En este estudio trataremos de demostrar, que desde tiempos antiguos hubo una estrecha relación entre los oráculos de Pariacaca y Pachacamac a través de caminos sobre las cuencas del Rímac, Lurín, Mala y Cañete. Esta relación no se reduce al carácter sacro de ambos, sino a una respuesta de control territorial y los recursos económicos, estructurado en un paisaje sagrado, donde se fundan los asentamientos a lo largo de ambos márgenes de estos ríos. Los asentamientos estuvieron interconectados por una red vial que fueron el soporte de una permeabilidad entre los pueblos. Sin embargo, a la llegada de los incas estos escenarios fueron incorporados a la administración inca a través de procesos violentos de enajenación de sus tierras, pueblos y deidades, implantándose instalaciones administrativas, sagradas y de almacenaje, consecuentemente la fisonomía del paisaje social y sagrado cambio y los caminos elevaron su nivel, convirtiéndose en Qhapaq Ñan, especialmente los de Pachacamac-Pariacaca-Xauxatambo por el valle de Lurín, el del valle de Mala y Cañete, cuyas rutas confluyen en la Cordillera del Pariacaca, escenario sagrado. Posteriormente, estas rutas, se utilizaron como instrumento de coerción que trastoco la estructura social de estos pueblos. Los argumentos que fundamentan este poder, es el control económico en su dimensión sagrada y simbólica, donde subyace el control de las fuerzas productivas, consecuentemente el control económico, como es la circulación de los bienes y servicios y principalmente las dicotomías: producción - consumo y almacenamiento - redistribución.

Palabras clave: Lurín; Qhapaq Ñan; Pariacaca; Pachacamac. 
Abstract: In this study, we will try to show that since ancient times there was a close relationship between the oracles of Pariacaca and Pachacamac through roads over the Rímac, Lurín, Mala and Cañete basins. This relationship is not reduced to the sacred nature of both, but to a response of territorial control and economic resources, structured in a sacred landscape, where the settlements are founded along both margins of these rivers. A road network that were the support of a permeability between the towns interconnected the settlements. However, upon the arrival of the Incas these scenarios were incorporated into the Inca administration through violent processes of alienation of their lands, peoples and deities, implanting administrative, sacred and storage facilities, consequently the appearance of the social landscape and sacred change and the roads raised their level, becoming Qhapaq Ñan, especially those of Pachacamac-Pariacaca-Xauxatambo through the Lurín valley, the valley of Mala and Cañete, whose routes converge in the Pariacaca mountain range, sacred scenery. Later, these routes were used as an instrument of coercion that upset the social structure of these peoples. The arguments that support this power, is the economic control in its sacred and symbolic dimension, which underlies the control of the productive forces, consequently the economic control, as it is the circulation of the goods and services and mainly the dichotomies: production - consumption and storage - redistribution.

Keywords: Lurín; Qhapaq Ñan; Pariacaca; Pachacamac.

SUMARIO: 1. Introducción. 2.Los asentamientos como espacio social en la cuenca de Lurín y Mala. 2.1. Espacio y poder. 2.2. Espacio sagrado. 2.3. Espacio simbólico. 3. Poder y Sacralización del paisaje entre Pachacamac y Pariacaca. 4. Los caminos: red de poder y violencia. 5. Los espacios sagrados en la cordillera del Pariacaca: estructura del poder simbólico y político. 5.1. Pirca Pirca. 5.2. Conjunto de canchas y corrales anexos a Pirca Pirca. 5.3. Tramo Pirca Pirca-La Escalera. 5.4. El abrigo rocoso de Cuchimachay; 5.5. Las escaleras. 6. Discusión. 7. Referencias Bibliográficas.

\section{INTRODUCCIÓN}

El estudio trata de manera puntual la ruta Pachacamac-Xauxatambo y de manera alternativa el valle de Mala que une directamente con Huarochirí, consecuentemente con el Qhapaq Ñan, por lo que formarían dos rutas que articulaban la costa y la sierra y a la vez, dos espacios sagrados, el centro ceremonial de Pachacamac y la Cordillera de Pariacaca, ambos con significación divina que corresponden a dos paisajes de oposición dentro de la mentalidad andina: Pariacaca como deidad serrana y Pachacamac como deidad yunga o de los llanos.

Geográficamente, la cordillera de Pariacaca se encuentra localizada entre las regiones de Lima y Junín, como una prolongación de la cordillera de los Andes y logra hasta 5860 m s. n. m. (Casaverde, 2017). En tanto que, al sur de la ciudad de Lima, a $30 \mathrm{~km}$ aproximadamente al margen del río Lurín se encuentra el centro arqueológico de Pachacamac, edificada sobre cuatro promontorios rocosos con depósitos de arena formados a causa del viento, con un clima característico de la costa 
central, es decir, árido, semicálido y húmedo, lo correcto para lugares cercanos al litoral (Pozzi y Uceda, 2019).

El primero está relacionado con el agua y las nieves, y el segundo a la mamacocha o mar. Este último también era una deidad con atributos de generar movimientos sísmicos; «el que hace temblar la tierra o el pachacuyuchic» (Ávila, 1966, p. 153). Según Rostworowski, Pachacamac también posee el atributo de representar a la oscuridad, mientras que su oponente antagónico Vichama posee el atributo de representar el día. Por consiguiente, ambos funcionan como una dualidad de oposición y están en lucha constante (Rostworowski 1983).

De manera análoga, también podemos hablar de la dualidad de Pariacaca-Pachacamac. Esta dualidad de oposiciones visible en los atributos de las deidades se configura en la vida e ideología de los pueblos, tanto de los yungas como de los pueblos de las partes altas. Este mecanismo ideológico fue al parecer uno de los móviles que impulsó a la administración inca en la ruta Pachacamac - Xauxatambo para viabilizar las conquistas y fijar referentes económicos y políticos ante los pueblos conquistados, de manera que esta relación podía haber minimizado los impactos de violencia social, debido a los actos de ocupación de los pueblos.

Nuestras investigaciones, en este sentido, vienen a ser un aspecto relacionado precisamente en los rasgos de violencia visibles en las trazas urbanas de los pueblos intervenidos por los incas. Este aspecto lo hemos venido advirtiendo ya en otros artículos luego de varios reconocimientos y trabajos de campo, y una revisión exhaustiva de documentos referidos a la etnohistoria, historia y arqueología de este escenario. Uno de los documentos más importantes es sin duda lo referente al manuscrito quechua de Huarochirí recopilado por Francisco de Ávila y traducido por José María Arguedas (1966) y Gerald Taylor (1999). Asimismo, es el resultado de largos períodos de investigación arqueológica en Pachacamac que nos ha permitido entender las relaciones e interacciones entre los pueblos, los dioses y la sacralidad de los paisajes.

\section{LOS ASENTAMIENTOS COMO ESPACIO SOCIAL EN LA CUENCA DE LURÍN Y MALA}

Los asentamientos arqueológicos no se han fundado en escenarios aislados, por lo general obedecen a un conjunto de otros asentamientos que de una u otra manera se encuentran articuladas a través de la socialización del paisaje y de una red vial que, en nuestro caso, se refiere al tramo Qhapaq Ñan Pachacamac-Pariacaca-Xauxatambo y recorre, en parte, la cuenca del rio Lurín luego Huarochirí hasta Xauxatambo en la cuenca del Mantaro.

A partir de lo expuesto, nos centraremos en entender los asentamientos como un paisaje social fijados a una red vial que atraviesa transversalmente, desde la 
costa pasando por la cordillera hasta el valle interandino del rio Mantaro donde se halla Xauxatambo durante el Intermedio Tardío. Sin embargo, este camino al unir Pachacamac con la cordillera del Pariacaca, se consagra como escenario de un paisaje sacralizado, contenedor de poder y escenario de lo sagrado. En el primero, se involucran las unidades de producción, almacenamiento, redistribución, consumo y un manejo del espacio urbano, que, en el fondo, son los indicadores de una estructura simbólica del poder. Estos indicadores en manos de una cúpula gubernamental como son los curacazgos o pequeñas jefaturas como las Canta, Huarochirí, Yauyos o ychsmas, sometieron a las poblaciones y aldeas vecinas, fijando limites que permiten delinear una territorialidad incipiente, que, en muchos de los casos, no son límites físicos, sino simbólicos y que perduraron hasta la llegada de los incas.

En tanto que el espacio sagrado enfatiza dos variables: una, referida a los espacios construidos para fines sacros, como los templos, adoratorios, ushnus, etc. y aquellos que se sacralizan a través de la práctica del rito y del mito en un tiempo hierático, como son las plazas, los caminos, las acequias, las apachetas, los cementerios, las lagunas, puquios, etc. Estos espacios son perceptibles en la organización del entorno como un paisaje integrado que guarda un "equilibrio» simbólico en la sociedad y están referidos a las montañas más altas, cuevas, puquios, lagos y lagunas, ríos, nevados, el mar, etc., configuran el pensamiento y cosmovisión del hombre costeño y serrano, por lo que en la materialización del espacio construido se percibe el paisaje construido. En consecuencia, se convierten en los referentes simbólicos y sagrados ligados a la fundación de los asentamientos donde el componente humano se apropia de estos espacios y los incorpora en su cosmos a través de varios actos y procesos de sacralización, como son la materialización de la conducta social y la construcción de los mitos de origen o mitos de fundación. Por lo cual, para la investigación se presume que el área de estudio se desarrolla en un espacio social conformado por tres componentes: a) Espacio y poder, b) Espacio sagrado y c) Espacio simbólico.

\subsection{Espacio y poder}

El espacio y el poder implican política territorial de los pueblos que han adquirido derechos frente al lugar donde se funda su asentamiento, que, a la vez, incorpora el paisaje sagrado que a través de su control y administración germina el poder, para ello, las cúpulas gubernamentales configuran los mecanismos de hegemonía y control. En este caso, tanto Pachacamac como Pariacaca configuran los ejes como polos de control y a la vez una interdependencia. Lo que se observa a partir de esta propuesta es que existió una articulación económica, política y religiosa entre Pachacamac, como centro ceremonial, y la cordillera del Pariacaca, como escenario de adoración a la deidad de las aguas, y el gran asentamiento de Pirca Pirca, como eje de control económico. Astuahuamán (2008) certifica que el carácter sagrado que se 
le atribuía al nevado justifica la espectacularidad del camino, los ídolos de roca en los adoratorios, los lugares de ofrenda y todas las partes de geografía sacralizada, asimismo reafirma el complejo sistema de rituales que se daban en los adoratorios que existían en este espacio sacralizado y custodiado en sus extremos por Pachacamac y Pariacaca.

La estructuración del espacio de alguna manera consagra el poder de cada pueblo que dependerá fundamentalmente como este potenciado las unidades de producción, de consumo y almacenamiento que se visibiliza en la materialización de los componentes arquitectónicos del asentamiento, llámese terrazas de cultivo, canales, acueductos, depósitos o colcas, etc. Para la estructuración del espacio se considera el uso y manejo del espacio urbano, donde es factible identificar las unidades funcionales y una posible estructura simbólica del poder. Farfán (2019) fundamenta que este poder podría ser sagrado o solo de carácter simbólico, pero detrás de ello existían factores que subyacen el control de las fuerzas productivas, por ende, el control económico. Asimismo, Llanos (2019) asegura que el manejo de los centros ceremoniales prehispánicos no solo cumplía función de satisfacer eventos ceremoniales sino de esferas puntuales para realizar transacciones comerciales.

\subsection{Espacio sagrado}

A partir de las últimas investigaciones en Pachacamac (Eeckhout y Farfán 2000; 2001; 2004), podemos decir que existe una tradición de sacralidad desde los primeros años de nuestra era en Pachacamac ( $100 \mathrm{~d}$. C.) convirtiéndose en un centro ceremonial de largo alcance que ha perdurado hasta la conquista de los incas, es decir, casi 1500 años. Pero su apogeo más relevante fue cuando se gesta la deidad Pachacamac en el Intermedio Temprano (100 a 800 d. C.), y adquirió fama a nivel regional.

En el Intermedio Tardío (1100 a 1470 d. C.) el crecimiento económico y una explosión demográfica en los andes centrales traen como consecuencia el crecimiento de los asentamientos, así como los conflictos y contradicciones dentro de los organismos sociales. Las pugnas generalmente son por asuntos de territorialidad y acceso a recursos. Cada curacazgo o jefatura se preocupa más por extender su territorio con fines de acceder a los recursos, pero surgen los conflictos étnicos debido a la disputa de dichos recursos (Rostworowski, 1978). La agudización de estos conflictos debió terminar, por lo general, en choques armados.

Se notan también, para el caso Pachacamac, un fenómeno de ritualidad traducido en la incorporación y popularización de una forma arquitectónica denominada "pirámide con rampa», cuya función es muy discutida en arduos debates por arqueólogos que han excavado estos edificios, de donde se desprenden dos hipótesis: una de carácter funcional, es decir, los que creen que se trata de edificios que representan a las distintas provincias sometidas a Pachacamac formando verdaderas embajadas, 
argumentando que se trata de edificios cívico-ceremonial (Paredes, 1991) o ceremonial cultista (Franco, 2004); en oposición a esta propuesta se propone, como hipótesis alternativa, que se tratarían de edificios o palacios para un curaca o rey que, a su muerte, es enterrado en la pirámide que luego es abandonada. Consecuentemente, es construida otra pirámide por su sucesor en otro lugar (Eeckhout, 2003). A esto el autor lo llama modelo de sucesión generacional de tipo dinástico, y por consiguiente el carácter funcional de las pirámides con rampa es secular antes que religioso.

Particularmente nosotros abordaremos la dimensión simbólica inherente a estos edificios en base a los componentes arquitectónicos y su asociación en relación a las deidades serranas tales como Pariacaca y una parentela divina que recorre las cordilleras y las zonas yungas, todas ellas subyacentes en el discurso mítico que integra un espacio simbólico de oposiciones -Pachacamac (yunga) y Pariacaca (santuario de altura)-, factible de identificar en los datos arqueológicos y los relatos orales que disponemos para su contrastación. Las evidencias arqueológicas de carácter sagrado con las que contamos en Pachacamac la conforman un sinnúmero de conopas y ofrendas halladas en distintos lugares de las pirámides con rampa relacionados a la venida del agua, lo que equivale decir dentro un contexto de rituales propiciatorios de culto al agua y las montañas sagradas generadoras de las lluvias, en este caso la Cordillera del Pariacaca. De este modo, Pachacamac y Pariacaca corresponderían a la misma esfera de una estructura simbólica, que funciona en la dimensión del tiempo desde periodos muy tempranos (Farfán, 2000). Por esta razón, para los fines de esta investigación, citaremos simultáneamente a ambos espacios para explicar el fenómeno sagrado.

\subsection{Espacio simbólico}

Pachacamac y Pariacaca como entes sagrados, mencionados por Astuahuamán (1999) como divinidades principales del Chinchaysuyo, corresponden a dos espacios dentro de un mismo eje simbólico, materializado por el río Lurín y un Camino Real o Qhapaq Ñan que atraviesa todo el valle y se eleva hacia las mesetas de Huarochirí para luego ingresar a la alta cordillera, escenario mítico citado por los documentos como la Cordillera de Pariacaca. Este itinerario, que une la costa y la sierra, permite también visualizar otras dos dimensiones: una de oposición y dualidad entre los dioses del llano y los dioses de las montañas, y otro como dimensión simbólica que encierra la circulación de las aguas desde las nieves perpetuas, a través de los ríos hasta desembocar en el mar, que, a su vez, permite la vida a lo largo del valle y principalmente en la zona yunga, lo que los convierte en dos espacios interdependientes una de la otra. Esta forma de ver la realidad estaba basada en una intencionalidad de formalizar y estructurar el espacio introduciendo en las mentalidades de los pueblos la relación y parentela divina entre las deidades Pachacamac y Pariacaca. Sin embargo, debemos advertir que estos mecanismos de formalización 
de la estructura sagrada ya en la época Inca fueron posible gracias a la existencia de bases sólidas de relaciones entre la costa y la sierra y de sus deidades antes de la llegada de los incas.

Los componentes del espacio simbólico se definen a partir de la conceptualización del cosmos y la organización del espacio simbólicamente conceptuado. Así tenemos la bipartición del espacio que define también el concepto de dualidad hanan y urin; mencionado por Yaya (2013) como la división de dos bandos en la dinastía real inca, basado en un principio de transformación en relación a la naturaleza y el espacio; la tripartición horizontal, collana, pallan, callao, según Cerrón (2005) estas designaciones se encuentran enlazadas con la organización social, territorial y religiosa del antiguo imperio y que representaban una jerarquía en términos sociales y religiosos. Y finalmente la tripartición vertical, conocido también como kaypacha, hananpacha y ukupacha, el mundo nuestro, el mundo de arriba y el inframundo, mencionado por Achig (2019) como las tres pachas, base de los Andes y como la estructura del pensamiento filosófico para determinar el espacio físico.

\section{PODER Y SACRALIZACIÓN DEL PAISAJE ENTRE PACHACAMAC Y PARIACACA}

La llegada de los incas al ámbito de los andes centrales trastoca los sistemas de asentamiento, así como las organizaciones sociales, pero lo más trascendental fue el manejo económico y la incorporación de un panteón religioso distinto a las poblaciones locales. Debemos advertir que antes de la llegada de los incas el tránsito entre Pachacamac y Pariacaca (figura 1) era por dos rutas bien definidas, una fue la ruta por el valle de Mala y la otra por el valle de Lurín. En estas rutas estaban emplazadas asentamientos de distintos tamaños, pero distantes entre sí por cortas distancias, que fluctuaban entre $1 \mathrm{~km}$ y $5 \mathrm{~km}$, lo que los hace altamente relacionados. La presencia de un centro ceremonial como Pachacamac en la zona yunga relacionada al mar lo convertía en un destino sagrado, por lo que su fama trascendió los límites de la zona yunga hasta las altas montañas, para lo cual, las rutas de acceso a Pachacamac se sacralizaron a través de equipamientos adicionales a los caminos, como los adoratorios de Chauymayanca, Ampuccasa, Cinco Cerros pishccachuri, (aún no sabemos si fue un adoratorio o lugar sagrado), Occsha lugar sacralizado debido a la gran batalla de Pariacaca con Huallallo, donde venció el primero; luego en la zona de Turmanyapaccha, en este mismo lugar se puede visualizar una gran piedra con dos horadaciones en forma cóncava a manera de pocitos, donde se ejecutaba algún rito al agua. Desde aquí el camino nos llevará hasta las inmediaciones de la laguna de Mullucocha, cuya sacralización evoca el lugar de las ofrendas de mullu a Pariacaca. Ascendiendo ya hacia el adoratorio de Pariacaca llegamos a Cuchimachay lugar sacralizado debido a la presencia de las Pinturas rupestres que antecede el ascenso a las escaleras. 


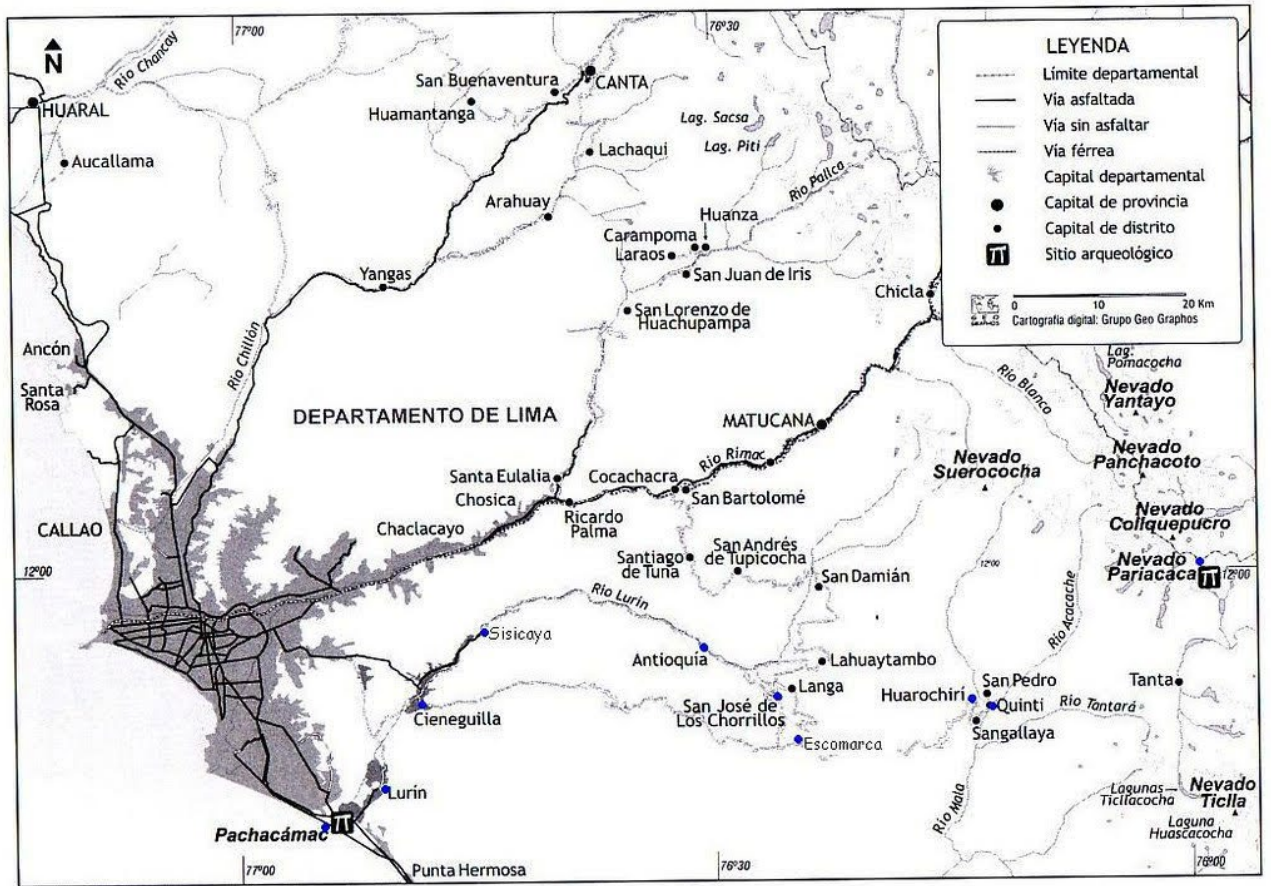

Figura 1. Mapa con la ruta inca Pachacamac-Pariacaca. Fuente: Felipe Valera.

Finalmente, la ruta de ascenso por las escaleras también formó parte de los espacios sacralizados por la presencia de importantes elementos arquitectónicos, tales como parapetos, plataformas, apachetas, etc., respaldado por Flores y Cuynet (2017), quienes aseguran que, como parte del pensamiento andino, la sacralización existe como hecho social, donde las divinidades son parte de la naturaleza y de la sociedad. Sin duda, todos estos componentes sacralizados no son casuales, forman parte de una ruta sagrada en ambas direcciones, de subida y bajada; Spalding (2008) confirma que esto puede ser apreciado en toda la ruta, siendo esto uno de los escenarios más espectaculares conservados en el área del antiguo Tahuantinsuyo, con notables obras de ingeniería, convirtiéndola en un magnífico sendero ceremonial que conectaba a los peregrinos con dos centros religiosos. De manera que la sacralización del paisaje estaba estructurada en un universo que articula el mar con los nevados, los oráculos de Pachacamac y Pariacaca y, de este modo, convertir estos escenarios en una sola unidad. Astuahuamán (1999) asevera que entre Pachacamac hacia lo largo del camino del Pariacaca los lugares han sido sacralizados, espacios que dan lugar a un complejo sistema de rituales, justificando la jerarquía que existe en la divinidad del mundo andino y como están emparentadas entre ellas. En este sentido, los incas al conquistar estos valles diseñaron una estrategia tomando en cuenta el territorio integrado al componente humano a través de los 
centros urbanos y rurales y estructuraron un modelo de control, tanto territorial como económico e ideológico. Vitry (2017) afirma que los incas, al poseer nuevos territorios, realizaban una repartición creando un ordenamiento territorial en términos sociales y productivos, lo cual se enlazaba con lo religioso o mítico, asimismo, Ayvar (2019) mencionan que la expansión inca combinada estrategias militares y sociales para asegurar la convivencia de los diversos grupos culturales.

De modo que la fundación o sometimiento de los asentamientos en un estado como el inca, no solo estaba limitada a las posibilidades sociopolíticas o económicas, sino que también estuvo referido a una racionalidad del uso y manejo del espacio, donde se superpone el paisaje sagrado y simbólico sobre el paisaje social, de manera que estas conquistas estuvieron cargadas de violencia, enajenación de sus tierras y poblados, convirtiéndolos en otra realidad. Esta es la razón por la cual el trazado urbano de los asentamientos de estos valles obedece a una planificación estratégica, a veces forzada, basada en esquemas funcionales, a la vez simbólicos, puesto que trasmiten, a través de la forma, un valor ideológico capaz de cohesionar y aglutinar a los grupos humanos conquistados. Estas posibilidades son importantes toda vez que el paisaje requiere de una interpretación en su dinámica y a la vez como estructuración de un sistema de formas que trasmite una significación.

\section{LOS CAMINOS: RED DE PODER Y VIOLENCIA}

El camino principal o Qhapaq Ñan es el que sale de Pachacamac por el valle de Lurín. Sin embargo, existe la ruta mucho más directa a través del valle de Mala y atraviesa por varios asentamientos entre los considerados grandes y pequeños, como los de Yuncaviri, Cochahuasi, Huancani, Minay, Torihuasi, Collahuasi, Checas, Huallinta y Coñe, entre los más importantes. Como se puede ver, los nombres de los sitios son muy significativos cuya toponimia alude posiblemente a su función, como las de Yuncaviri = de los yungas; Cochahuasi = Casa del agua o lagunas; Huancani = ¿Del Huanca?; Collahuasi = Casa de las collas. A manera de ejercicio muy elemental de toponimia, hemos visto que estos sitios guardan una relación significativa y simbólica con la función que cumplieron, al parecer, en tiempo de los incas se transforman estos sitios o se fundan para afianzar el poder y dominación sobre los pueblos originarios. Todos estos asentamientos tienen los rasgos incas, basado en la arquitectura implantada, lo que presupone una intervención muy violenta sobre estos asentamientos, como los de Yuncaviri, Minay, Checas, Huallinta, donde es visible la transformación de la traza urbana con infraestructura netamente inca. Para materializar estas transformaciones el poder inca mandó destruir instalaciones ya existentes que estaban emplazados en espacios preferenciales a fin de instaurar un nuevo orden construyendo infraestructuras nuevas o remodelaciones, como se puede visualizar en la traza urbana, obviamente estos actos se presumen que 
fueron violentos y como único testimonio de estos actos son las construcciones impuestas y la destrucción de las infraestructuras anteriores, porque es visible las diferencias, tanto en el sistema constructivo, como en los modelos arquitectónicos implantados. Asimismo, es visible también un camino que une a estos pueblos y conducen hacia Sangalla y San Lorenzo de Quinti, desde donde debería empalmar con el Qhapaq Ñan hacia Pariacaca siguiendo la quebrada Marga.

En cambio, la ruta del Qhapaq Ñan que sale desde Pachacamac se proyecta por el valle de Lurín; lo peculiar es que se inicia desde un espacio sagrado atravesando las tres murallas hasta la portada del valle, desde donde el camino continúa por la margen derecha del valle. En esta trayectoria, debemos señalar, entre Pachacamac y la quebrada Tinajas, existen varios asentamientos prehispánicos tardíos como los de Pampa de Flores A y B, un asentamiento con 14 pirámides con rampa. Para muchos este asentamiento es similar a Pachacamac por la cantidad de edificaciones piramidales con rampa, lo que indicaría claramente una relación muy estrecha con Pachacamac. También existe muy cerca de Pampa de Flores el llamado Tambo Inga; al parecer, formaba parte del equipamiento físico del camino inca. Desde la quebrada Tinajas se continúa por la misma margen hacia el área de Cieneguilla, en donde también hay tres asentamientos importantes: Tijerales A y B y Panquilma. Debemos tener claro que todos estos asentamientos son de tamaños considerables y poseen también edificaciones piramidales con rampa, lo cual confirma una relación muy estrecha con Pachacamac con la tradición Ychsma. Estos asentamientos por la envergadura e importancia y la organización territorial ychsma poseen características estratégicas de localización, visibilidad y fundamentalmente actividad económica y altamente concentrada con grandes depósitos de almacenamiento y también debió ser densamente poblada. En estos asentamientos también la presencia inca fue intensa, con grandes instalaciones administrativas, patios, depósitos que modificó la traza urbana. La imposición de instalaciones incas en estos asentamientos trastoca el orden antiguo, para lo cual se destruyeron instalaciones para construir otras e incluso se notan modificaciones de las ya existentes. Aquí surgen preguntas que nos preocupan: ¿las evidencias en la traza urbana y la arquitectura con manufactura inca nos estarían indicando que hubo arreglos pacíficos para instaurar un nuevo orden? $\mathrm{O}$ es que realmente fue violento, ¿cuáles serían los actos violentos para instaurar otro orden? Hay pues aún problemas oscuros de cómo fue el impacto y la toma del territorio ychsma que incluía Pachacamac.

Luego de este grupo de asentamientos que acabamos de nombrar seguimos el cauce por la margen derecha y encontramos el asentamiento Molle con ausencia de edificaciones piramidales con rampa. A partir de esta zona todos estos asentamientos están emplazados en los conos de deyección de las quebradas laterales del valle con escasos espacios de cultivo. La geomorfología comprende el lecho de río con un monte ribereño muy escaso. Las estribaciones laterales son de fuerte pendiente y de formaciones rocosas aflorantes que han impedido crear asentamientos más arriba 
de las faldas. Pero no debemos olvidar que una gran parte de estos asentamientos corresponden al Intermedio Tardío un periodo de alto crecimiento poblacional, lo que significa que antes de la llegada de los incas el valle ya tenía una población en asentamientos a lo largo de la red vial. Como vemos, el valle se angosta aún más y los espacios de cultivo son mucho más escasos, de lo que se desprende la ausencia de asentamientos grandes en este tramo, excepto Chontay un asentamiento aglutinado construido a base de piedra y revestimiento de barro. Aquí ya estamos sobre los $800 \mathrm{~m} \mathrm{s.} \mathrm{n.} \mathrm{m.,} \mathrm{en} \mathrm{este} \mathrm{asentamiento} \mathrm{no} \mathrm{hay} \mathrm{muchos} \mathrm{rasgos} \mathrm{inca,} \mathrm{sin} \mathrm{embargo,}$ existe una instalación completamente inca y está a escasos $500 \mathrm{~m}$ de Chontay; se le denomina Santa Rosa y está conformado por construcciones cuadrangulares que definen 16 depósitos alineados en una fila semicircular y otras construcciones anexas como son espacios rectangulares en 7 niveles de 10 recintos cada uno, totalizando 70 recintos que debieron ser áreas de almacenamiento, lo cual justifica la presencia Inca en esta parte del valle y más que nada un control directo sobre Chontay. Siguiendo río arriba llegamos a Cicicaya pueblo Tambo Real, según Guamán (1980, p. 1079), aunque cuando hicimos la prospección no vimos construcciones que puedan asignarse como tambo, es probable que la actual población los haya destruido para ampliar sus áreas de cultivo o fue el actual poblado.

Luego seguirá hasta Antapucro y Chaymallanca dos asentamientos prehispánicos en ambas márgenes izquierda y derecha respectivamente. Este punto es límite superior del valle de los asentamientos con tradición costeña entrando ya a la tradición serrana aguas arriba (Eeckhout, 1995). Hasta aquí los asentamientos visibles y significativos, luego son esporádicas las evidencias ocupacionales debido a la estrechez del valle hasta Antioquia a $1550 \mathrm{~m} \mathrm{s.} \mathrm{n.} \mathrm{m.} \mathrm{Siguiendo} \mathrm{el} \mathrm{curso} \mathrm{del} \mathrm{río} \mathrm{aguas}$ arriba hasta Cruz de Laya, se pueden notar esporádicamente antiguas terrazas y el camino prehispánico, pero hoy abandonados. En este lugar del valle se bifurca dos quebradas, una hacia el Sur-Este en dirección a San José de Los Chorrillos y la otra en dirección Nor-Este, hacia San Damián, en cuyas alturas esta la naciente de este río. Sin embargo, el Qhapaq Ñan continúa en dirección a Lahuaytambo, pasando por el pie del cerro Ampuccasa, y se dirige hacia Saclinta, que es un sitio con presencia de chulpas, plataforma y recintos, con significación sagrada que se ubica en una zona alta sobre el Qhapaq Ñan. Seguidamente se llega Canlle un antiguo tambo, según la nómina del Qhapaq Ñan. Sin embargo, a 450 m hacia el Sur en la parte alta en las faldas del cerro Matahua se notan construcciones ligeramente aglutinadas con recintos ortogonales en un área de $300 \mathrm{~m}, 150 \mathrm{~m}$, sobre una planicie. De este punto se dirige hacia Lahuaytambo, luego al Tambo de Huancasana, para luego llegar a los 4100 m s. n. m. y avanzar hacia Huarochirí, no antes de pasar por el gran asentamiento arqueológico de Suni, que preside Huarochirí desde la parte alta, para luego ingresar a la localidad de Huarochirí. En Suni existe una gran plaza empedrada al pie de una gran roca a manera de huanca y fue el espacio sagrado de este asentamiento que está relacionado al Qhapaq Ñan. 
De Huarochirí sigue el Qhapaq Ñan pasando por San Pedro de Huancaire y San Juan de Tantarache donde hemos identificado un tambo evidentemente asociado al camino inca. En esta parte de cuenca alta del rio Mala que corresponde a la esfera Huarochirí no hemos identificado rasgos considerables de los incas; no sabemos cuáles fueron las razones. Saliendo de la esfera Huarochirí, en San Juan de Tantarache, se retoma el camino siguiendo la quebrada Marga hasta el abra de Ocsha, a 4700 m s. n. m., que es un abra que divide las nacientes del río Mala y Cañete. Ocsha es ya el espacio que corresponde a la esfera de Pariacaca con afloramientos de rocas calcáreas. Se sigue hacia Tambo Real y el asentamiento de Pirca Pirca; es aquí donde el rasgo inca se convierte en un instrumento avasallador debido a que se halla Tambo Real y el gran asentamiento de Pirca Pirca, ambos conectados por una red de caminos (Casaverde, 2014). El asentamiento de Pirca Pirca, ubicado a los $4400 \mathrm{~m} \mathrm{~s}$. n. m., se convirtió en una articulación de los poderes económicos entre la costa y la sierra (Farfán, 2019), aquí fue notorio el impacto de imposición inca en la modificación de la traza urbana de este asentamiento, se nota la kallanca, depósitos o colcas, edificios ovoides con recintos al interior, construcciones trapezoidales, grandes corrales con edificios administrativos, la gran plaza, etc., es decir, este asentamiento fue elegido por los incas como un enclave de poder estratégico en la dimensión política, económica, simbólica y sagrada. La instauración del nuevo orden en Pirca Pirca inobjetablemente también sugiere acciones violentas mucho más severas por la gran cantidad de instalaciones que prácticamente modificaron el antiguo orden urbano.

En este territorio de puna el camino toma dos direcciones a partir de Turmanyapaccha: una hacia Tambo Real y el asentamiento de Pirca Pirca, ubicado en la margen derecha del río Carhuamayo; el otro por la margen izquierda en dirección a la Escalera, llamada también Cuchimachay (Bonavia, 1972; de Diez, 1978) donde existen las famosas pinturas rupestres.

\section{LOS ESPACIOS SAGRADOS EN LA CORDILLERA DEL PARIACACA: ESTRUCTURA DEL PODER SIMBÓLICO Y POLÍTICO}

\subsection{Pirca Pirca}

El asentamiento de Pirca Pirca se remonta al Intermedio Tardío (siglo XI d.C.) y su fundación se originó debido a la presencia de un importante recurso natural basado en los pastizales que abundan, base de una economía ganadera. Los fundadores quizá sean los grupos yaros adoradores de Libiac. Ya en los documentos del siglo XVI y XVII se sostiene que Pariacaca era de origen Yaro (de la Espada, 1881). El tiempo de su auge debió ser de gran trascendencia regional, tanto por su fama religiosa como por el poder económico que ya ejercía, por lo que los incas al llegar a 
esta zona asumieron el control total de la economía y lo integraron a su plan geopolítico de conquistas e integración.

Los componentes arquitectónicos de los edificios al parecer conformarían espacios simbólicos o religiosos que aún nos falta identificar. Pero estas edificaciones impuestas guardan relación con el gran impacto de apropiación y violencia con el que se impusieron los incas en este asentamiento. Pirca Pirca antes de la llegada de los incas debió tener otra configuración, quizá más aglutinada, basada en recintos circulares con pasajes, y un flujo de circulación generado por el propio crecimiento. No hay murallas, su desarrollo y crecimiento es espontáneo, basado en agrupamientos habitacionales que definen patios familiares, hasta se puede hablar de barrios, quizá cuatro. Pero a la llegada de los incas se transforma y se modifica la traza, y se impone una gran plaza central de $29 \mathrm{~m}$ de ancho por $30 \mathrm{~m}$ de largo, para lo cual se debió destruir varios recintos afectando quizá todo un barrio. Esta plaza principal está rodeada de varios recintos típicamente del modelo inca, de formas cuadrangulares con vanos de acceso central. Se construye también una kallanca de $41.70 \mathrm{~m}$ de largo por $18.70 \mathrm{~m}$ de ancho con dos accesos, uno hacia el lado suroeste en la parte central y la otra en el ángulo sur del recinto. Este hecho debió concitar un impacto en la vida de los habitantes; algunos debieron ser reubicados, otros desalojados. Lo cierto es que hay una modificación sustancial, tanto en la traza como en las unidades familiares que cambió de modo drástico la configuración urbana. En el extremo sur del asentamiento, se construyó tres instalaciones muy peculiares. Se trata de dos espacios cerrados de forma ovalada en cuyo interior se han construido recintos rectangulares todas distanciadas entre sí de manera que definen un patio central el acceso es por el noreste en ambos casos y se trata de un acceso complejo debido a que hay un vestíbulo que limita el acceso con dos vanos. Un poco más al sur se halla otra instalación similar con las mismas características, pero de forma cuadrangular.

Pirca Pirca está integrada al gran conjunto de corrales y canchas emplazadas en la inmensa altiplanicie sobre la margen derecha del riachuelo Carhuapampa. Sin embargo, debe quedar claro que ambos conjuntos - el habitacional y las canchas - fueron fundados al mismo tiempo, puesto que se notan estructuras que integran ambos conjuntos. También es de notar que el camino ingresa directamente al asentamiento y a la vez separa ambos conjuntos.

\subsection{Conjunto de canchas y corrales anexos a Pirca Pirca}

Este conjunto de espacios abiertos es una clara manifestación del inmenso poder económico y control territorial del estado Inca. Su integración a la economía estatal ocasionó varios cambios, debido a que, al parecer, ya había corrales antiguos sobre los cuales se hicieron ampliaciones con diseños mucho más organizados, quizá basado en una significación simbólica conforme a la forma que adoptan las estructuras en su conjunto. Nosotros estamos mostrando sólo una parte de este 
equipamiento, pero, aun así, es visible un ordenamiento del espacio configurando ocho canchas adyacentes entre sí, pero que están dotadas también de uno o tres recintos. En la actualidad estas canchas están siendo utilizadas por los ganaderos en períodos estacionales. En el lado sur se nota la presencia de un área con restos de lascas de riolita y otro tipo de rocas, indicando claramente que hubo un taller lítico en esta parte. Al extremo sur se construyó un conjunto de cinco recintos rectangulares con los vanos de acceso al centro, una típica instalación del modelo inca. Definen un patio común, lo que conforma un sector habitacional quizá de algún funcionario encargado de las instalaciones. Al extremo oeste continúan las instalaciones de canchas.

\subsection{Tramo Pirca Pirca-La Escalera}

Este tramo es quizá el más importante del Qhapaq Ñan, ya que es posible identificar la trayectoria en todas sus manifestaciones de ritualidad y simbologías. Topográficamente se eleva 200 m desde Pirca Pirca hasta La Escalera, y atraviesa una geomorfología muy accidentada y de alta erosividad. Este tramo, al igual que La Escalera, son las que le han dado fama de un camino de difícil tránsito para atravesar la cordillera. Hay dos factores visibles en su construcción: uno es que fue construido adosada a la roca madre, y otra es que el camino se articula con el abrigo rocoso de Cuchimachay con pinturas rupestres. Si entendemos que cuando se construye el camino, ya existían estas pinturas, debemos entender que la tradición o mitificación de esta cueva debió tener fuerte repercusión en el tiempo, y tanto los yaros, los llacuaces y luego los incas integraron a su cosmovisión los contenidos simbólicos de esta cueva. Es más, se incrementaron tardíamente pinturas en otras rocas. Esta parte del camino encierra un enorme valor simbólico e histórico debido a que está concentrado en el escenario del adoratorio principal de Pariacaca, por lo menos así lo confirman los documentos (de la Espada, 1881; Taylor, 1999; Itier, 2000).

En cuanto a la configuración del trazo de camino desde Pirca Pirca, vemos que se desarrolla por la margen izquierda del riachuelo Palcamayo, para tomar un rumbo noreste hacia Masho. Este pequeño caserío es de pastores, y habitan entre 4 a 5 familias de manera temporal. En este lugar nos informaron que a Pariacaca también se le denomina Tullujuto, que de acuerdo a su significado podría llamarse «el que roe (come) hueso». En este caso, el mullu por su naturaleza dura vendría a ser el «hueso». Precisamente en la traducción de Arguedas se menciona que cuando el Inca mandó que se le ofrendara comida a Macahuisa, este le dijo «yo no suelo comer estas cosas y le pidió que le trajera mullu, lo devoro al instante, icap, cap!, rechinaban sus dientes mientras masticaba» (Ávila, 1966, p. 76). No obstante referirse a Macahuisa, el significado se le puede atribuir también a Pariacaca, toda vez que es el padre de Macahuisa. 
De Masho -que está ubicado a $300 \mathrm{~m}$, al pie del camino-, se sigue hacia La Escalera, para lo cual se retoma el Qhapaq Ñan llegando a Antaracra, Yanama, Pomaruri y Casharuri por trazos muy visibles cuyos anchos varían de acuerdo a la topografía, ya escaleras, ya alineamientos de piedra, ya taludes aterrazados que van cambiando hasta ascender a la laguna de Mollucocha. Aquí toma el borde superior oeste de la laguna, hasta llegar a las inmediaciones de Plazayoc, que es la intersección de la quebrada Atarhuay con el Camino Inca.

Desde Plazayoc asciende una escalinata en zigzag, construido en la roca madre con tecnología de adosamiento y construcción de taludes y pavimentos empedrados, por tramos angostos y por tramos anchos hasta de $12 \mathrm{~m}$ y se ingresa a la cuenca glaciar de La Escalera no antes de pasar por un lugar denominado culebrayoc. Por zonas el camino sortea pantanos y se adosa a los peñascos sobre el cual está construido el camino hasta llegar a las inmediaciones del abrigo rocoso de Cuchimachay y la laguna de La Escalera.

\subsection{El abrigo rocoso de Cuchimachay}

Está conformado por cuatro grandes bloques de roca de naturaleza granodiorita que se han desprendido desde las partes altas del cerro San Cristóbal y han quedado apoyados unos sobre otros, formando un gran vacío en el interior de 20 a $30 \mathrm{~m}$ en sus extremos más amplios. La altura máxima en el interior es de $12 \mathrm{~m}$. Los cuatro bloques forman dos aberturas en el techo por donde penetra la luz solar. En los cuatro bloques se han identificado pinturas rupestres de distinta característica al que lo hemos denominado Frentes A, B, C, D y E. El interior es bastante húmedo en temporadas invernales almacenándose agua hasta cubrir parte del espacio del Frente A. El bloque de este frente proyecta una línea de reparo (sombra) de $13 \mathrm{~m}$ en el exterior, lado oeste, donde se nota mayor actividad ocupacional debido a la presencia de abundante material de desecho, desde lascas y puntas de proyectil hasta fragmentos de cerámica inca.

La distribución de los frentes para ejecutar las pinturas obedece a un criterio de «fundación» del espacio desde donde se sacraliza por primera vez con la presencia del Frente $A$, que son los diseños más complejos y extensos. Su diseño más característico es un camélido en estado de preñez donde se resalta el vientre del animal, mientras que la cabeza y las patas son muy reducidos. Sin duda, corresponde a períodos muy tempranos conforme lo corroboran el material asociado, conformado por puntas de proyectil. Luego durante su existencia, el abrigo fue consolidando su carácter sagrado dentro de las mentalidades, ya no de cazadores y recolectores solamente, sino también de pastores pertenecientes a sociedades más tardías, cuando se ejecutan trazos y diseños distintos al Frente $A$. Se continuó pintando las rocas en esta cuenca glaciar a los cuales las hemos denominado Bloques 1, 2, 3 y 4. Estos bloques están alineados en dirección a la laguna de Sorao al pie del flanco 
Este del nevado Pariacaca. El Qhapaq Ñan está pasando a escasos $50 \mathrm{~m}$ del abrigo rocoso y continúa hacia Las Escaleras pasando por los bloques 1 , 2 y 3 . El bloque 4 está más arriba. Nuestros primeros trabajos de 1982 y 1983, fue precisamente concentrado en el abrigo rocoso y su contexto circundante, donde realizamos una prospección con excavaciones restringidas y el levantamiento planimétrico del abrigo, así como secciones y calcos de las pinturas. Las primeras conclusiones se basaron tanto en los resultados de la excavación, como en la identificación de los diseños pictográficos, tanto del abrigo Cuchimachay, como de los bloques pétreos 1, 2, 3 y 4 , concluyéndose que estas corresponden a varias fases de elaboración, y por consiguiente a varios momentos de la ocupación del sitio. Los diseños están relacionados a la representación de animales de caza y animales domesticados o en proceso de domesticación, lo cual indica una larga secuencia ocupacional. Las excavaciones de cuatro pozos de sondeo nos permitieron inferir que la ocupación en este sitio tuvo una etapa precerámica debida a la presencia de carbón y ceniza sin cerámica, y que continuó hasta la época colonial (Farfán, 2010; Aramburu, 2014).

\subsection{Las escaleras}

El tramo de Las Escaleras quizá sea una de las secciones del Qhapaq Ñan con mayor contenido simbólico y sagrado, debido a que se desarrolla desde las inmediaciones del abrigo a través de escalinatas construidas para un tránsito ritual. Hemos dividido en 23 tramos las escaleras, puesto que cada tramo guarda una característica peculiar, tales como descansos y muros transversales que restringen un acceso masivo. Hay tramos demasiado estrechos debido a la presencia de formaciones rocosas o porque la naturaleza de este tramo así lo requiere, es decir, limitar el acceso o cumplir una serie de requisitos previos. También los tramos nos sugieren que había cuidantes $u$ oficiantes que residían en estos lugares permanentemente $o$ en fechas fijas.

Las escaleras terminan en una pequeña abra donde el camino llega a un espacio abierto, al parecer una plaza empedrada. Se halla a un costado del camino, hacia el lado Norte, en un espacio ligeramente elevado. Desde esta plaza sale un camino en dirección norte en ascenso donde no hallamos nada referente al mentado adoratorio, pero sí otras marcas en los farallones rocosos, en lo alto del cerro.

El Qhapaq Ñan continúa siguiendo la trayectoria en dirección noreste por el borde Norte de otra cuenca glaciar conformada por la laguna de Pumarauca y otras menores. En estos tramos hay apachetas formadas por los que vienen de Jauja antes de llegar a La Escalera. El camino es cómodo, por zonas hay escalones, hasta alcanzar una altura considerable donde hay otra laguna, desde donde se divisa el abra de Portachelo a $4600 \mathrm{~m} \mathrm{~s}$. n. m. que es el divortium aquarum que desciende hacia la vertiente oriental; es decir, hacia el Mantaro. El camino toma una trayectoria norte hacia las altiplanicies de Shacshamachay siguiendo por el lado sur del 
cerro Shacucrumi hasta la laguna de Acococha. El camino sigue por el lado sur de esta laguna y muy cerca, avanzando un kilómetro aproximadamente, encontramos un montículo con construcciones que podría ser un tambo pequeño ya en la cuenca del Huaylacancha camino a Cochas, donde el camino se hace más difuso debido a que fue disturbado por los pastores actuales.

\section{DISCUSIÓN}

El tema que tratamos es demasiado denso, con distintos problemas que abordar, pero hemos intentado centrar nuestra atención en cómo los incas, al incursionar hacia Pachacamac y los valles de Lurín, Mala y Cañete, utilizaron mecanismos coercitivos y violentos, como muestran las evidencias en la implantación de infraestructuras propias del modelo inca y orientado a controlar y ejercer el poder sobre los pueblos conquistados. La mayoría de los asentamientos tienen el sello inca, a través de la incorporación de instalaciones administrativas. Pero debemos señalar de manera categórica que, en todos los casos, las instalaciones incas se han superpuesto en las áreas más significativas de los pueblos. Para materializar estos actos se han tenido que destruir los preexistentes o modificar en base a remodelaciones y cambios de uso, como vanos clausurados, muros adicionales, implantación de elementos trapezoidales, ya en ventanas, hornacinas, plantas de patios y plazas. Tomando en cuenta estos criterios, este trabajo se dedica principalmente al conocimiento de la traza urbana y encontrar indicios de manifestaciones simbólicas cargados de ritualidad que estarían ligados a una cosmovisión compleja que involucra a dos espacios, la sierra cordillerana y la zona yunga asociada a lomas y el mar; a dos deidades, Pachacamac y Pariacaca, ligados por una estructura de sacralidad que fueron instrumentos y mecanismos de control.

Los datos que sustentan estos hechos están dispersos en documentos y visitas y en reconocimientos de campo. Lo que estamos observando a partir de estos datos, es que existe una articulación económica, política y religiosa entre Pachacamac como santuario y la Cordillera del Pariacaca como escenario de adoración a una deidad de las aguas, con tres atributos: la de cordillera o montaña sagrada, como deidad ligada a los yaros y llacuaces y como oráculo Apu y Wamani reconocido regionalmente y Pachacamac como deidad ligada a los Ychsmas yungas y el mar.

En torno a este fenómeno, a lo largo de la historia, se han estructurado mitos y leyendas, ritos y peregrinaciones y se construyeron instalaciones e infraestructuras a lo largo del Qhapaq Ñan. En tiempos del Intermedio Tardío, estos territorios ya tenían tradición de peregrinaciones hacia Pariacaca, por lo que los incas habrían encontrado una costumbre establecida con rutas sagradas cargadas de mitos y leyendas. Lo que hicieron fue integrar y fortalecer este instrumento y usarlo a favor del estado, para lo cual, mejoraron los caminos e incorporaron nuevas formas de 
ritualidad mucho más regional, y por ello Pachacamac y Pariacaca toman otros matices, para lo que se construyen historias fabulosas a fin de legitimar la invasión y apropiación de los territorios por los incas. Estas historias, contenidas en el manuscrito de Huarochirí, integran a través de los mitos ambos territorios y lo convierten en espacios simbólicos y duales.

Pero ¿cómo fueron estos cambios? ¿Fueron controlados por el estado Inca de manera pacífica o violenta?, y ¿cómo fueron capaces de manipular los íconos sagrados, tanto de la zona yunga, como de la sierra? ¿Hubo rebeliones étnicas? ¿O fueron alianzas estratégicas con los antiguos curacas o jefes de los yauyos e ychsmas? ¿Por qué tanta modificación en la traza urbana de los pueblos con el sello inca? ¿Qué fue de las instalaciones locales y cómo fueron destruidas? Obviamente no hay referentes concretos para explicar estos hechos, pero se presume por las evidencias que fueron forzadas y violentas. Al revisar la organización del espacio de Pirca Pirca en Pariacaca, vemos que las instalaciones incas están emplazadas forzadamente en el antiguo poblado, para lo cual se debió destruir otras instalaciones; no sabemos si eran edificios principales o comunes. De no ser así, debieron estar basados en acuerdos pacíficos.

En Ñaupahuasi, asentamiento que fue capital de los yauyos, también se notan claramente la transformación del espacio urbano con características forzadas. En Pachacamac sucede lo mismo, muchas de las pirámides con rampa fueron transformadas y modificadas por los incas para adecuar a nuevas funciones y generar nuevas formas de poder. Ni que decir de las instalaciones mayores, como el templo de Punchucancha o del Sol (Taylor, 1999), el Acllahuasi, el Ilamado Palacio de Taurichumpi, solo por citar las más importantes en Pachacamac. Aquí también se nota cómo la antigua traza urbana de Pachacamac se transformó, y esto no pudo ser del todo pacíficamente, se arrebataron espacios "preferenciales», con la consecuente destrucción y construcción de otras; esto es evidente. El manejo del espacio urbano para la remodelación, al parecer, fue dividido en dos espacios: el lado oeste, que fue elegido para la construcción del Templo del Sol junto a los antiguos templos, pero tomando en cuenta la parte más alta de jerarquía y con vista al mar. El Acllahuasi, de la misma manera, estaba cerca de la laguna de Urpihuachac, relacionado a la fertilidad, y el lado Este, dedicado íntegramente a las instalaciones civiles donde se concentran casi todas las pirámides con rampa. Vemos pues, que los incas sabían la dimensión de control territorial y religioso de los ychsmas así como de los yauyos, por lo que se implementó políticas de conciliación y políticas de coerción para controlar un territorio, una población étnicamente diversa y deidades de tradiciones muy arraigadas.

Una de las infraestructuras administrativas de mucha importancia son los tambos de carácter público, que se construyeron para cada jornada de camino. Sin embargo, la presencia de un gran asentamiento a los 4400 m.s.n.m., como es Pirca Pirca, se habría convertido en un enclave que articulaba el poder económico entre 
la costa y la sierra a tal punto que se adecuaron grandes corrales para llamas de carga y la población local, al mismo tiempo que se había transformado en un asentamiento administrativo de control.

En este asentamiento se adecuaron una gran plaza central con construcciones de planta cuadrangular a la usanza inca y una gran kallanca, además de otros equipamientos sagrados, que estaría indicando la jerarquía que había adquirido en época de los incas esta aldea, de lo cual se deduce que esta parte de la cordillera con este poblado controlaba un vasto territorio dentro de un contexto sagrado que ejercía de por sí un poder. Los tambos también formaron parte de la política integracionista de carácter coercitivo de parte de los incas. Otros elementos sagrados, tales como huacas locales, cerros, e incluso las pinturas rupestres, fueron integrados al panteón inca, y así los incas fortalecieron su poder frente a los pueblos conquistados. De este modo el poder político y el poder simbólico fueron armas muy efectivas para la política de conquista de territorios y grupos sociales organizados que poco a poco fueron integrados al estado Inca.

\section{REFERENCIAS BIBLIOGRÁFICAS}

Achig, D. (2019). Cosmovisión Andina: categorías y principios. Revista de la Facultad de Ciencias Médicas, 37(3). https://doi.org/10.18537/RFCM.37.02.01

Aramburu, D. (2014). Patrón de asentamiento prehispánico: uso, manejo del espacio y recursos en los valles de Chicha Soras/Sondondo, Apurímac-Ayacucho.

Astuahuamán, C. (1999). El «Santuario de Pariacaca». Alma Mater, (17).

Astuahuamán, C. (2008). Pariacaca: un oráculo imperial andino. Ensayos en Ciencias Sociales, 1(2), pp. 15-54.

Ávila, F. (1966). Dioses y hombres de Huarochirí: narración quechua recogida por Francisco de Ávila [¿1598?]. Traducción castellana de José María Arguedas.

Ayvar, Z. (2019). Los incas: organización y gestión de recursos. Revista Balance's, $7(9)$

Bonavia, D. (1972). El arte rupestre de Cuchimachay. Pueblos y Culturas de la sierra Central del Perú (pp. 134-139). Lima 
Casaverde, G. (2017). Definiendo la cronología relativa en los caminos: el camino del Pariacaca. Boletín del Museo Chileno de Arte Precolombino, 22(2), pp. 6581. https://www.redalyc.org/articulo.oa?id=359954608005

Casaverde, G. (2014). Caminos y sitios del Pariacaca. En P. Van Dalen, Arqueología de las cuencas alto y medio andinas del Departamento de Lima (pp. 117-139). Lima: Fondo Editorial de la Universidad Nacional Mayor de San Marcos.

Cerrón, R. (2005). La onomástica de los ceques: cuestiones etimológicas. Lexis, 29(2), pp. 285-303.

de Diez, M. (1978). Señoríos indígenas de Lima y Canta. Instituto de estudios peruanos.

de la Espada, M. (1881). Relaciones geográficas de Indias. (Vol. 1). Tip. de MG Hernández.

Eeckhout, P. (1995). Pirámide con Rampa N³, Pachacamac: Resultados Preliminares de la Primera Temporada de Excavaciones (Zonas $1 \&$ 2). Bulletin de l'Institut français d'études andines, 24(2), pp. 102-156.

Eeckhout, P. (2003). Ancient monuments and patterns of power at Pachacamac, central coast of Peru. Beiträge zur allgemeinen und vergleichenden Archäologie, 23, pp. 139-182.

Eeckhout, P. (2003). Diseño arquitectónico, patrones de ocupación y formas de poder en Pachacamac, Costa central del Perú Architectural design, occupation patterns and power structures in Pachacamac. Revista española de antropología americana, 33, pp. 17-37.

Eeckhout, P. y Farfán, C. (2000). Proyecto Ychsma. Investigaciones Arqueologicas y Estudios de Restauraciones en el Sitio de Pachacamac, Primera temporada (1999).

Eeckhout, P. y Farfán, C. (2001). Proyecto Ychsma. Investigaciones Arqueologicas y Estudios de Restauraciones en el Sitio de Pachacamac, Segunda temporada (2000).

Eeckhout, P. y Farfán, C. (2004). La Temporada 1999 de Excavaciones Arqueológicas en la Pirámide con Rampa III de Pachacamac, Costa Central del Perú. Tipshe, 4, pp. 161-182. 
Farfán, C. (2000). La Ocupación Inca en Cantamarca, Canta. Arqueología y Sociedad, 13, pp. 173-198.

Farfán, C. (2010). Poder simbólico y poder político del estado inca en la cordillera del Pariacaca. Lima: Universidad Nacional Federico Villarreal.

Farfán, C. (2019). Pachacamac y Pariacaca: interacción de sacralidad y poder político. En O. Llanos, Los centros políticos ceremoniales o las ciudades (pp. 143-172). Lima: Amaruquipus editores.

Flores, L. y Cuynet, F. (2017). Cuando el mito se vuelve piedra: memorias alrededor de estelas pukara en el norte del Titicaca, Perú. Chungará (Arica), 49(1), 35-48. https://doi.org/10.4067/S0717-73562017005000011

Franco, R. (2004). Poder religioso, crisis y prosperidad en Pachacamac: del Horizonte Medio al Intermedio Tardío. Bulletin de l'Institut français d'études andines, 33(3), pp. 465-506. https://doi.org/10.4000/bifea.5074

Guamán, F. (1980). Nueva corónica y buen gobierno. (Vol. 2). Fundación Biblioteca Ayacucho.

Itier, C. (2000). Lengua general y quechua cuzqueño en los siglos XVI y XVII.

Llanos, O. (2019). Los centros políticos ceremoniales o las ciudades conceptualizando las dinámicas del poder, la jerarquía y el manejo del espacio en la América prehispánica. Lima: Amaruquipus editores.

Paredes, P. (1991). Pachacamac. Los Incas y el antiguo Perú. 3000 años de historia. Centro Cultural de la Villa de Madrid, Ayuntamiento de Madrid. Quinto Centenario.

Pozzi,D.yUceda,C.(2019).ElmuseoPachacamacenelsigloXXI.Chungará(Arica),51(2), pp. 253-269. https://doi.org/10.4067/S0717-73562019005001404

Rostworowski, M. (1978). Señoríos indígenas de Lima y Canta. Instituto de Estudios Peruanos.

Rostworowski, M. (1983). La tasa ordenada por el Licenciado Pedro de la Gasca (1549). Revista histórica, 34, pp. 53-102. 
Spalding, K. (2008). Consultando a los ancestros. En M. Curatola y M. Ziółkowski, Adivinación y oráculos en el mundo andino antiguo. Lima: Fondo Editorial de la Pontificia Universidad Católica del Perú.

Taylor, G. (1999). Ritos y tradiciones de Huarochirí. Instituto francés de estudios andinos.

Vitry, C. (2017). El rol del Qhapaq ñan y los Apus en la expansión del Tawantinsuyu. Boletín del Museo Chileno de Arte Precolombino, 22(1), pp. 3549. https://doi.org/10.4067/S0718-68942017005000103

Yaya, I. (2013). Hanan y Hurin: historia de un sistema estructural inca. Bulletin de I'Institut français d'études andines, 42(2), pp. 173-202. https://doi.org/10.4000/ bifea.4049 